\title{
Biomedical and health research geography in the Eastern Mediterranean Region
}

\author{
Ghazi O. Tadmouri, ${ }^{1}$ Ahmed Mandil ${ }^{2}$ and Arash Rashidian ${ }^{2}$
}

${ }^{1}$ Faculty of Public Health, Jinan University, Tripoli, Lebanon. ${ }^{2}$ Department of Science, Information and Dissemination, WHO Regional Office for the Eastern Mediterranean, Cairo, Egypt. (Correspondence to: Ahmed Mandil: mandila@who.int).

\begin{abstract}
Background: Measuring scientific outputs allows for objective evaluation of established health research systems and ranking countries according to scientific achievements. To our knowledge, attempts for systematic mapping health research output in the Eastern Mediterranean Region (EMR) are limited.
\end{abstract}

Aims: We aimed to conduct a detailed bibliometric analysis of EMR biomedical and health research productivity during the period 2004-2013, considering country of first author.

Methods: We applied an improved PubMed search strategy to obtain precise data on EMR research productivity, limiting articles to reviews, original research and case reports. Data were normalized to global research output, represented by total articles indexed in PubMed per year from 2004-2013, according to population size of each country. Second order polynomial trend lines were calculated and comparing 5-year periods: 2004-2008 with 2009-2013.

Results: Inspecting overall raw data, a clear increasing trend is observed. Regional share of global health related research ranged from $0.85-2.36 \%$ of total PubMed indexed publications during the study period. Five countries contributed to $80 \%$ of all published articles during study period; i.e., Islamic Republic of Iran (39\%), Egypt (14\%), Saudi Arabia (11\%), Tunisia, and Pakistan (8\% each). Overall, 2.35 articles are published per 100000 population per year. While Kuwait maintained the highest per capita publication (followed by Tunisia, Lebanon, Qatar and Islamic Republic of Iran), Qatar, Islamic Republic of Iran and Saudi Arabia demonstrated the highest "per capita" population growth in publications. Three academic institutions accounted for over $10 \%$ of all publications that were led by an investigator from the Region. Collectively, most prolific 25 EMR institutions published $44 \%$ of all published biomedical and health research in the EMR.

Conclusions: The overall global share of EMR health research publication is smaller than its global share of population or wealth. Biomedical and health research needs greater encouragement and supporting many EMR countries and/or institutions, especially those found to be least prolific in our analysis. The increase in academic publication on health has been more prominent in a few countries only. It is anticipated that the concentration of biomedical and health research in EMR academic institutions would help in translating knowledge into public health outcomes, if more suitable conditions are provided.

Keywords: Eastern Mediterranean Region, PubMed, bibliometrics, biomedical research, health research.

Citation: Tadmouri GO; Mandil A; Rashidian A. Biomedical and health research geography in the Eastern Mediterranean Region (2004-2013). East Mediterr Health J. 2019;25(10):728-743. https://doi.org/10.26719/emhj.19.082

Received: 08/07/19; accepted: 25/09/19

Copyright (C) World Health Organization (WHO) 2019. Some rights reserved. This work is available under the CC BY-NC-SA 3.0 IGO license (https:// creativecommons.org/licenses/by-nc-sa/3.o/igo).

\section{Introduction}

In the growing world of science and technology, scientific research forms an important foundation of every country's success. Health research enables health systems to develop evidence-based interventions that would, ultimately, lead to the improvement of health indicators in corresponding populations (1), based on sound health-policy making.

Globally, including countries of the Eastern Mediterranean Region (EMR), knowledge production and publication has been on the rise. Still it seems that EMR countries publish less academic output per capita than the global average (2). Moreover, health related research is unevenly distributed in the Region (3), although a comprehensive picture is lacking. While the World Health Organization (WHO), and related global health policy assemblies, emphasize the importance of linking research evidence to policy-making and building research capacity (4), limited academic output from the Region may reduce the relevance of research evidence to regional priorities $(5,6)$. Unfortunately, limited success has been achieved in the EMR in adopting and prioritizing national health research agendas, or to systematically map research output in health and related biomedical domains $(7,8)$.

Measuring scientific outputs allows for objective evaluation of established health research systems and ranking countries according to their scientific achievements. Such analysis is an increasingly important part of a broader set of evaluation methods that could be used to analyse research trends, identify emerging areas of science, aid in resource allocation decisions, and support the decision-making process in health care $(9,10)$. To do this, a family of methods is applied including case study analysis, peer review, economic rate-of-return 
analyses and surveys, measurement of health indicators, and numbers of patents filed, in addition to quantitative analysis of health research outputs - also known as bibliometrics (11).

There is now widespread agreement that bibliometric methods have much to offer as a complement to narrative accounts of scientific developments and conventional evaluation processes with a view to strengthening them $(9,12,13)$. The increasing popularity of bibliometric analysis derives in part from the multitude of comprehensive infometrics indicators it offers, including activity measurement, knowledge transfer measurement, linkage measurement, inter-disciplinarity, and citation analysis $(14,15,16)$. More importantly, bibliometrics offer the special advantage of using seemingly objective data that can be collected with minimal involvement from the researchers themselves. This helps reduce the administrative burden posed on researchers by many of the alternative classical evaluation methods, while ensuring that the data gathered are more likely to be representative because they are gathered for entire research communities, not simply those researchers who give their consent (17). Additionally, bibliometric studies could be successfully used to assess trends in the scientific productivity of individual researchers, research groups, or research communities over time, and identify research gaps and priorities. (18,19-23).

In the biomedical and health fields, scientists and health researchers utilize many high quality citation databases to search for published literature. Of these databases, PubMed is the most significant "barrierfree" biomedical resource available on the World Wide Web (24); it provides a strong health discipline indexing coverage and catalogues over 28 million biomedical articles in more than 44000 journals in 37 languages (25).

The free access of PubMed and its friendly interface have led to the development of elaborate techniques to analyse global trends for biomedical and health research productivity, and to provide objective and useful tools to evaluate the results of scientific activity in different locations worldwide $(2,26,27,28)$. The EMR encompasses 21 Member States, namely: Afghanistan, Bahrain, Djibouti, Egypt, Iraq, Islamic Republic of Iran, Jordan, Kuwait, Lebanon, Libya, Morocco, Oman, Pakistan, Qatar, Saudi Arabia, Somalia, Sudan, Syrian Arab Republic, Tunisia, United Arab Emirates (UAE), and Yemen. In this region, early attempts to study the geographical distribution of biomedical article outputs took place in the Gulf Corporation Council (GCC) region $(29,30,31)$, including thorough quantitative bibliometrics for the UAE and Saudi Arabia (32-39).

More recently, a series of publications embarked on analysing biomedical and health research in individual countries of the EMR, including Egypt, Islamic Republic of Iran, Lebanon, Libya, Morocco, Oman, Pakistan, Palestine, Qatar and Tunisia (40-55). Most of these investigations included geographical distribution studies and quantitative analysis of medical publications from EMR countries by using either raw data or normalized data according to population size and gross domestic product (GDP) spending. Region-wide studies of health-related publications are rare, and are focused on specific topics of interest (20), and hence do not provide a comprehensive view of research products from the region.

To the best of our knowledge, this study represents the largest comprehensive attempt to analyse the collective biomedical and health research outputs in countries of the EMR. By aiming at the detailed bibliometric analysis of biomedical and health research productivity in EMR Member States during the period 2004-2013, results from this study may open up interesting opportunities for a more strategic approach to decision-making in research policy over the long term.

\section{Methods}

We have applied an improved PubMed search strategy (http://www.ncbi.nlm.nih.gov/pubmed/) to obtain precise data on biomedical and health research productivity in countries of the EMR; details are accessible in the publication by Tadmouri et al. (56). This current search strategy involved the use of elaborate syntaxes that are based on an original process, which was developed in 2004 (57). Non-sensitive and sensitive search strategies, including the names of EMR countries were directed to PubMed within the same day. For some countries, variant names in several world languages were also incorporated in the search syntaxes to cover non-English citations.

The resulting country-specific datasets were collected in "Medline format" text files and then imported into offline local databases, and were subject to quality checks to manually remove any articles with false positive addresses or those with address affiliations referring to countries of the EMR, but not belonging to first authors. This task became more imperative because at the beginning of October 2013 the National Library of Medicine (NLM) ceased performing quality control review and editing of the author affiliation field in citations indexed in PubMed, and started to rely on data supplied directly by journal publishers (58). Furthermore, NLM changed its policy from indexing the affiliation of the first author only, to including affiliations of all authors in every citation in the PubMed database for citations indexed after October 2013. These two major reasons limited our analysis to the decade including years 2004-2013. The time period also reflects the bibliographic strategies of PubMed, as by 2013 only the corresponding address of the first author was documented in PubMed. Hence, the analysis provides a picture of the healthrelated research publications as led by a researcher from the Region. As a result, publications in which an author from outside the Region is the leading author are excluded from this exercise.

Since address-based search on PubMed automatically excludes letters to the editors and commentary articles, published articles investigated in this study were limited to reviews, journal articles, and case reports. In addition, the type of search utilized in this study 
restricts results to papers in which the principal investigators are affiliated to institutions located in an EMR country. Although this could be considered as a possible limitation, the choice of selecting papers with main authors being from EMR institutions reflects a major involvement in the health research publication, and can give a fair representation of research directions in biomedical sciences in the Region, as well as to make sure that each article is assigned to a unique country and to avoid the presence of overlapping results.

The numbers of biomedical and health articles originating from countries of the EMR in years 20042013 were used as indices of total biomedical research production in these respective countries, as reflected by PubMed search. To allow for a balanced comparison, data were normalized to global research output, represented by the total number of articles indexed in PubMed per year from 2004-2013, and according to the population size of each country. For the latter, historical population data were obtained from the International Data Base maintained by the United States Census Bureau (59). Second order polynomial trend lines were used in the graphical representations to allow for better comparisons during the 5-year periods, i.e., 2004-2008 and 2009-2013. This characteristic is not possible to obtain by using linear polynomial trend lines, whereas higher order polynomials may portray unwanted noise.

\section{Results}

\section{Overview of biomedical and health research article outputs in the EMR}

By inspecting the overall raw data for biomedical and health research productivity in the EMR, a clear increasing trend is observed (total: 140911 articles; mean: 14091 articles per year with the leading author from EMR). Notably, the Islamic Republic of Iran accounted for nearly $39 \%$ of the overall sum of published research articles in the EMR (Table 1). Egypt follows with a share of 14\%, Saudi Arabia 11\%, Tunisia 8\%, and Pakistan $8 \%$. These five most-performing countries contributed to nearly $80 \%$ of all published biomedical and health-research articles in the EMR during 2004-2013. According to the World Bank Group's economic classification, most of the performing countries in the EMR belong to the lower- and upper-middle income categories (Supplement 1). All other remaining countries in the Region had contributions of values less than $4 \%$ of the overall biomedical and health-research publications in the EMR (Table 1).

Overall data from the EMR when normalized to global biomedical citation outputs indexed in PubMed indicate a meager, but expanding, contribution of $0.85-2.36 \%$ of global biomedical research output for years 2004-2013 (mean: 1.61\%; Table 1). Population adjusted data from the EMR reaffirm the progress in biomedical research outputs in the Region over the studied period, i.e., 1.014.24 publications/100 000 population for years 2004-2013 (mean: 2.35 publications/100 ooo population; Table 1).
Collectively, countries of the EMR witnessed a five-fold increase in the number of articles published annually between years 2004 and 2013 (Table 1, Figure 1.a) compared to an overall global growth in published biomedical research articles of $179 \%$ for the same period (Table 1). At a country level, the Islamic Republic of Iran achieved an ascending figure in term of growth of health research productivity from years 2004 to 2013, totaling almost $1061 \%$ increase (Figure 1.b). During the same period, Egypt achieved an overall growth of $410 \%$ with a steady growth in the periods 2004-2008 and 2009-2013 (Figure 1.c). However, Saudi Arabia doubled its growth in the same periods from $112 \%$ in years 2004 2008 to $248 \%$ in years $2009-2013$; hence, achieving an overall growth of $340 \%$ (Figure 1.d). An opposite trend is observed in Tunisia, which witnessed a gradual decrease in the rate of biomedical research productivity starting in year 2012 (Figure 1.e).

When results of biomedical and health-research article outputs from countries of the EMR are normalized to population size, an interesting array is displayed (Figure 2). Overall in the EMR, 2.35 biomedical research articles are published per 100000 population per year. Despite the fluctuations observed in the studied period (Table 1), Kuwait is a top performer with an average of 12.78 biomedical research papers published per 100000 population per year for the years 2004-2013 (Figure 2). Tunisia, suffering from an apparent declining trend over the last few years (Figure 1.f), publishes an average of 10.91 health-research articles per 100000 population per year (Figure 2). Lebanon follows with an average of 9.66 health-research articles per 100000 population per year. Qatar almost tripled its rate of health-research publications per 100000 population per year from an average of 6.42 articles in year 2004 to a record value of 17.73 articles in year 2013 (Figure 1.g), resulting with an overall average of 9.31. These latter figures are in complete match with an independent study evaluating Qatar biomedical publications indexed in PubMed for years 2000-2012 (52). Although the Islamic Republic of Iran has an average rate of 7.17 articles per 100000 population per year (Figure 2), the country achieved a 10-fold increase from a meager average of only 1.64 publications in year 2004 to a sizeable 15.53 publications per 100000 population per year for year 2013 (Figure 1.h). At a broader scale, most of the performing countries with regard to this indicator belong to the middle and highincome countries (Supplement 1).

\section{Institutional biomedical and health research article outputs in the EMR}

The geographical distribution of data on biomedical and health-research outputs in countries of the EMR was analysed at a higher resolution down to the institutional level (Table 2). Exhaustive review of the institutional affiliations for first authors in PubMed-indexed articles resulted in resolving not less than 1398 unique addresses (data not shown). Nearly half of these addresses are 


\begin{tabular}{|c|c|c|c|c|c|c|c|c|c|c|c|}
\hline Country & 2004 & 2005 & 2006 & 2007 & 2008 & 2009 & 2010 & 2011 & 2012 & 2013 & Total \\
\hline I.R. Iran & 1169 & 1643 & 2459 & 3832 & 4301 & 4930 & 6104 & 7972 & 10511 & 12401 & 55322 \\
\hline Egypt & 871 & 1003 & 1153 & 1383 & 1597 & 1949 & 2415 & 2866 & 3085 & 3569 & 19889 \\
\hline Saudi Arabia & 893 & 884 & 887 & 936 & 1004 & 1227 & 1620 & 2073 & 2440 & 3038 & 15002 \\
\hline Tunisia & 502 & 690 & 869 & 1016 & 1188 & 1334 & 1407 & 1531 & 1455 & 1403 & 11395 \\
\hline Pakistan & 378 & 563 & 629 & 738 & 973 & 1165 & 1404 & 1556 & 1669 & 1934 & 11009 \\
\hline Morocco & 255 & 306 & 346 & 402 & 447 & 518 & 567 & 707 & 870 & 978 & 5396 \\
\hline Lebanon & 261 & 312 & 379 & 389 & 459 & 430 & 450 & 484 & 546 & 624 & 4334 \\
\hline Jordan & 235 & 273 & 316 & 341 & 390 & 481 & 476 & 471 & 486 & 531 & 4000 \\
\hline Kuwait & 255 & 305 & 287 & 305 & 324 & 302 & 322 & 348 & 325 & 367 & 3140 \\
\hline UAE & 165 & 192 & 206 & 202 & 266 & 274 & 321 & 382 & 355 & 464 & 2827 \\
\hline Oman & 121 & 116 & 130 & 158 & 185 & 224 & 219 & 250 & 271 & 356 & 2030 \\
\hline Qatar & 53 & 73 & 71 & 80 & 90 & 122 & 176 & 195 & 271 & 362 & 1493 \\
\hline Iraq & 37 & 67 & 92 & 91 & 110 & 111 & 127 & 118 & 219 & 235 & 1207 \\
\hline Sudan & 67 & 74 & 70 & 86 & 102 & 112 & 112 & 145 & 147 & 164 & 1079 \\
\hline Syrian A. Rep. & 32 & 42 & 29 & 37 & 49 & 57 & 86 & 99 & 121 & 123 & 675 \\
\hline Palestine & 23 & 30 & 41 & 55 & 69 & 72 & 71 & 80 & 89 & 113 & 643 \\
\hline Bahrain & 56 & 50 & 58 & 52 & 40 & 49 & 40 & 65 & 65 & 81 & 556 \\
\hline Libya & 9 & 15 & 30 & 30 & 44 & 45 & 57 & 37 & 54 & 56 & 377 \\
\hline Yemen & 24 & 31 & 23 & 26 & 30 & 42 & 58 & 42 & 44 & 52 & 372 \\
\hline Afghanistan & 7 & 2 & 3 & 7 & 9 & 17 & 15 & 15 & 22 & 23 & 120 \\
\hline Djibouti & 1 & 3 & 1 & 3 & 5 & 7 & 5 & 5 & 5 & 4 & 39 \\
\hline Somalia & 0 & 0 & 0 & 0 & 2 & 0 & 1 & 0 & 1 & 2 & 6 \\
\hline EMR & 5414 & 6674 & 8079 & 10169 & 11684 & 13468 & 16051 & 19441 & 23051 & 26880 & 140911 \\
\hline World & 636339 & 698051 & 745048 & 783468 & 833467 & 874055 & 937453 & 1014330 & 1080155 & 1141118 & 8743484 \\
\hline Percentage & 0.85 & 0.96 & 1.08 & 1.30 & 1.40 & 1.54 & 1.71 & 1.92 & 2.13 & 2.36 & 1.61 \\
\hline Population Size* & 535786 & 546724 & 557954 & 568627 & 579444 & 590836 & 602005 & 612708 & 623505 & 634534 & - \\
\hline Articles/100 000 & 1.01 & 1.22 & 1.45 & 1.79 & 2.02 & 2.28 & 2.67 & 3.17 & 3.70 & 4.24 & Av. 2.35 \\
\hline
\end{tabular}

*Values indicated are in thousands. Source: United States Census Bureau, 2018.

Dark-coloured regions indicate years of higher productivity.

EMR row indicates the overall combined values for all EMR countries.

World/Percentage rows show the overall biomedical article \% values for the EMR normalized to global citation outputs registered in PubMed for the period from 2004 to 2013.

Articles per 100000 population rows show overall articles indexed in PubMed for the EMR normalized to corresponding population size (articles per 100000 population) for the period from 2004 to 2013.

located in few high and middle income countries, including the UAE (12\%), Iraq (11\%), Islamic Republic of Iran (11\%), Sudan (8\%), Kuwait (5\%), and Jordan (5\%). In several countries, a handful of institutions were responsible for a majority of health-research publications (e.g., Bahrain, Lebanon, Libya, Oman, Qatar, Yemen, and others). In other countries, a large number of institutions do share, in small fragments, the load of published research in health (e.g., Afghanistan, Iraq, Islamic Republic of Iran, Pakistan, Saudi Arabia, UAE, and others; Table 2).

Detailed address analysis indicates that universities and affiliated teaching hospitals are the major conductor of health and biomedical research in the EMR. This observation seems to be unchanged across low, lower- and upper-middle, and high-income countries (Supplement 1). In many EMR countries, universities - including campuses, associated hospitals, and research centers seem to have the upper hand in biomedical and health research (e.g., Jordan: 69\%, Lebanon: 84\%, Libya: 76\%, Palestine: 75\%, Tunisia: 72\%, and Yemen: $85 \%$, and in Morocco, Oman, and Qatar, hospitals seem to host a sizeable share of biomedical research (Table 2). In the EMR, Tehran University of Medical Sciences was observed to be the most prolific health research publisher during the study period, where first authors affiliated to the university contributed to $6 \%$ of all health research published in the Region between years 2004 and 2013. Both, Shahid Beheshti University of Medical Sciences (Islamic Republic of Iran) and King Saud University (Saudi Arabia) followed with a contribution of 3.2\% for each. Other research institutions had contributions that were less than $2.5 \%$. Only two research centres are featured among the most prolific institutions in the EMR, namely: King Faisal Specialist Hospital and Research Center (Saudi Arabia), and the National Research Center (Egypt). Collectively, the most prolific 25 institutions in EMR published $44 \%$ of all health research published in the Region (Table 3).

It is worth mentioning that the extraction of institutional details for the EMR necessitated overcoming the major obstacle imposed by the discrepancies in the 
Figure 1 Annual raw counts of biomedical and health research articles indexed in PubMed for years 2004-2013 for the (a) EMR, (b) Islamic Republic of Iran, (c) Egypt, (d) Saudi Arabia, (e) Tunisia, (f) Pakistan, (g) Morocco, and (h) Lebanon

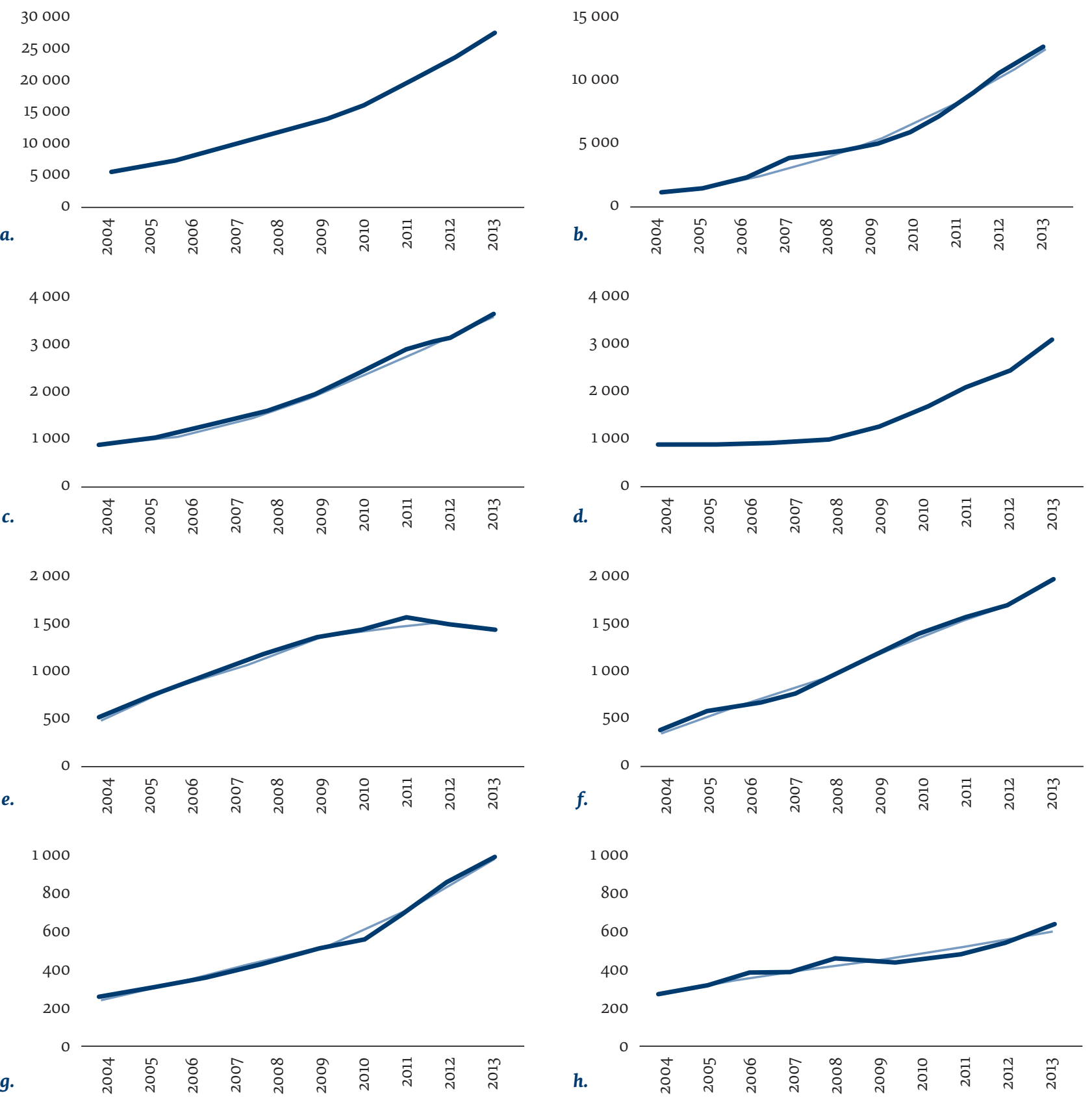

Thin lines represent corresponding second order polynomial trend lines for the two 5-year periods 2004-2008 and 2009-2013.

proper spelling of institutional names and the presence of several name variants for many institutions in the Region. This observation was also well documented in previous bibliometric attempts $(37,60)$. In a recent study that overviewed medical institutions in the Islamic Republic of Iran, Isfahan University of Medical Sciences had 27 name variants, while Tehran University of Medical Sciences had 21, Shiraz University of Medical Sciences had 20, and Iran University of Medical Sciences had 18 (61). Without any doubt, the presence of many name variants complicates the efforts to automatically retrieve information pertaining to research activity for a particular institution, and leads to an underestimation of its research output as derived from bibliometric research.
The importance of correct spelling in institutional affiliations is a subject that should be emphasized constantly. Allowing this uncontrolled divergence results in ambiguous representation of the regional distribution of biomedical and health research and improper rating of scientific institutions in the EMR.

\section{Discussion}

\section{The most performing EMR countries}

The populations of Egypt, Islamic Republic of Iran, and Saudi Arabia account for $30 \%$ of the total size of population in the EMR (59). Yet, these countries are all respon- 
Table 2 PubMed-indexed article counts (\#) and percent shares (\%) of the 10 most prolific institutions, universities, or hospitals in corresponding countries of the EMR for years 2004-2013

\begin{tabular}{|c|c|c|c|c|c|c|c|}
\hline \multirow[t]{2}{*}{ Country } & \multicolumn{2}{|c|}{ Top 10 Institutions } & \multicolumn{2}{|c|}{ Top 10 Universities } & \multicolumn{2}{|c|}{ Top 10 Hospitals } & \multirow[t]{2}{*}{ Total } \\
\hline & \# & $\%$ & $\#$ & $\%$ & \# & $\%$ & \\
\hline I.R. Iran & 29492 & 53.3 & 29492 & 53.3 & 2537 & 4.6 & 55322 \\
\hline Egypt & 13748 & 69.1 & 12881 & 64.8 & 939 & 4.7 & 19889 \\
\hline Saudi Arabia & 9903 & 66.0 & 8138 & 54.2 & 3325 & 22.2 & 15002 \\
\hline Tunisia & 8733 & 76.6 & 8156 & 71.6 & 4198 & 36.8 & 11395 \\
\hline Pakistan & 5599 & 50.9 & 5500 & 50.0 & 1028 & 9.3 & 11009 \\
\hline Morocco & 3642 & 67.5 & 2968 & 55.0 & 2750 & 51.0 & 5396 \\
\hline Lebanon & 3700 & 85.4 & 3619 & 83.5 & 1886 & 43.5 & 4334 \\
\hline Jordan & 3021 & 75.5 & 2771 & 69.3 & 267 & 6.7 & 4000 \\
\hline Kuwait & 2394 & 76.2 & 1749 & 55.7 & 580 & 18.5 & 3140 \\
\hline UAE & 1807 & 63.9 & 1652 & 58.4 & 452 & 16.0 & 2827 \\
\hline Oman & 1735 & 85.5 & 1149 & 56.6 & 851 & 41.9 & 2030 \\
\hline Qatar & 1259 & 84.3 & 310 & 20.8 & 464 & 31.1 & 1493 \\
\hline Iraq & 707 & 58.6 & 675 & 55.9 & 76 & 6.3 & 1207 \\
\hline Sudan & 754 & 69.9 & 653 & 60.5 & 55 & 5.1 & 1079 \\
\hline Syria A. Rep. & 523 & 77.5 & 307 & 45.5 & 39 & 5.8 & 675 \\
\hline Palestine & 487 & 75.7 & 481 & 74.8 & 29 & 4.5 & 643 \\
\hline Bahrain & 476 & 85.6 & 253 & 45.5 & 39 & 7.0 & 556 \\
\hline Libya & 302 & 80.1 & 287 & 76.1 & 44 & 11.7 & 377 \\
\hline Yemen & 331 & 89.0 & 317 & 85.2 & 11 & 3.0 & 372 \\
\hline Afghanistan & 61 & 50.8 & 5 & 4.2 & 24 & 20.0 & 120 \\
\hline Djibouti & 39 & 100.0 & 2 & 5.1 & 25 & 64.1 & 39 \\
\hline Somalia & 6 & 100.0 & 1 & 16.7 & 1 & 16.7 & 6 \\
\hline EMR & 37008 & 26.3 & 37008 & 26.3 & 7908 & 5.6 & 140911 \\
\hline
\end{tabular}

Institutional data include universities, hospitals, research centers, and others.

Figure 2 Biomedical research publications from countries of the EMR normalized to corresponding population size for years 2004-2013

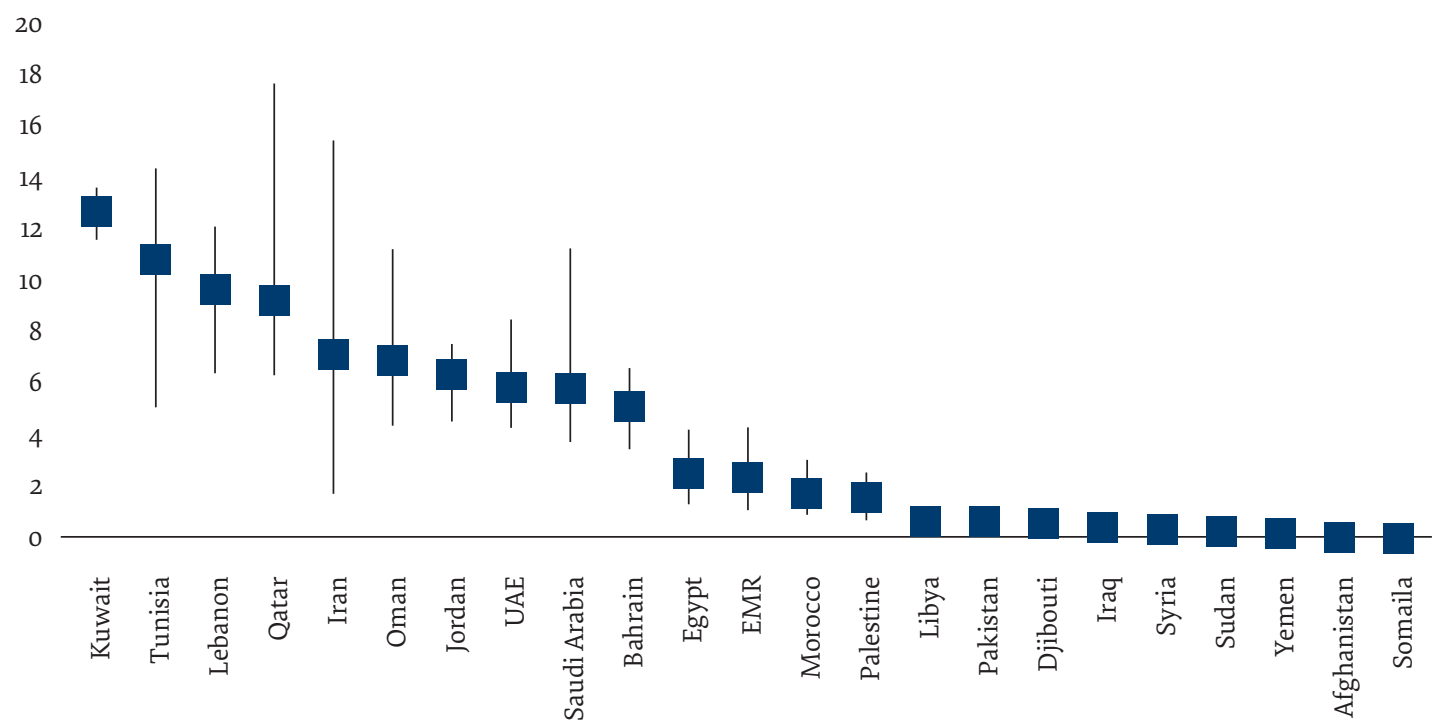

Values indicate health research publications per 100 ooo population per year.

Boxes represent means and vertical lines represent minimum-to-maximum ranges.

The entry «EMR» represents average overall values for the entire Eastern Mediterranean Region. 
Figure 3 Annual rates of biomedical and health-research articles indexed in PubMed for the (a) EMR, (b) Kuwait, (c) Tunisia, (d) Lebanon, (e) Qatar, (f) Islamic Republic of Iran, (g) Oman, and (h) Jordan, and normalized to corresponding population size for years 2004-2013

a.
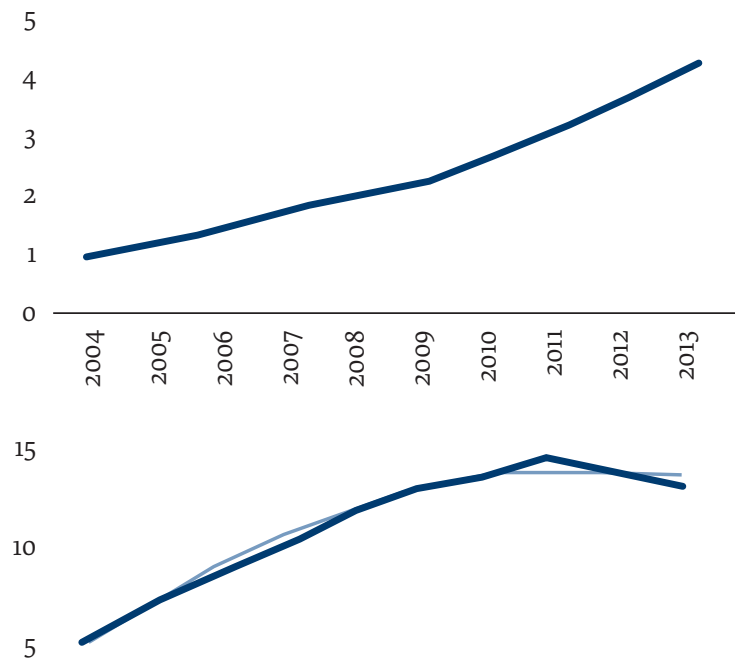

c.

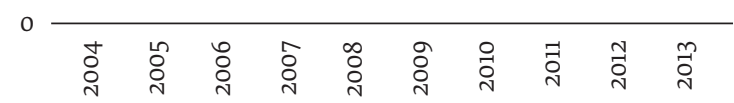

e.

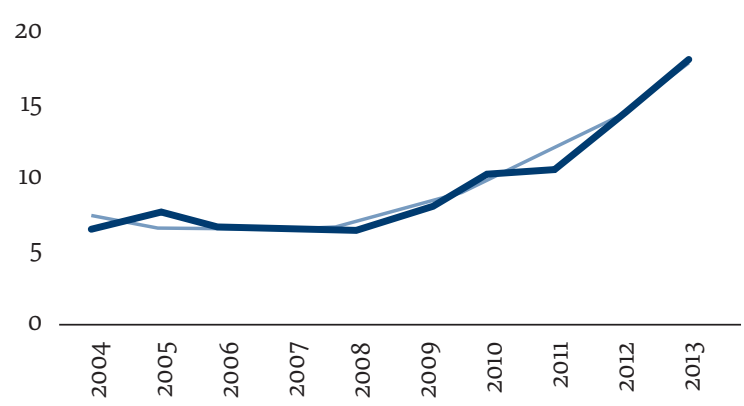

g.

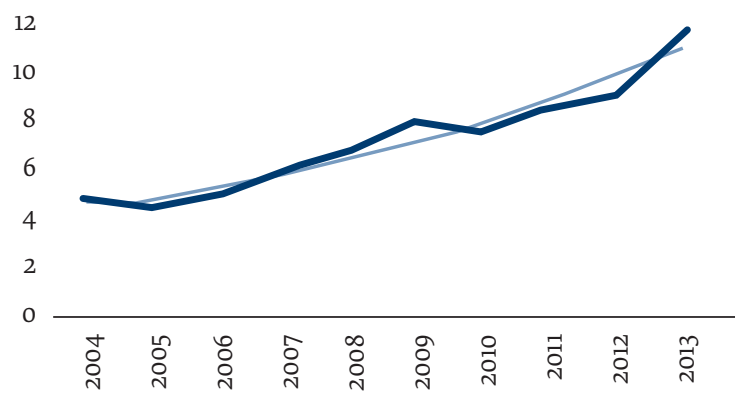

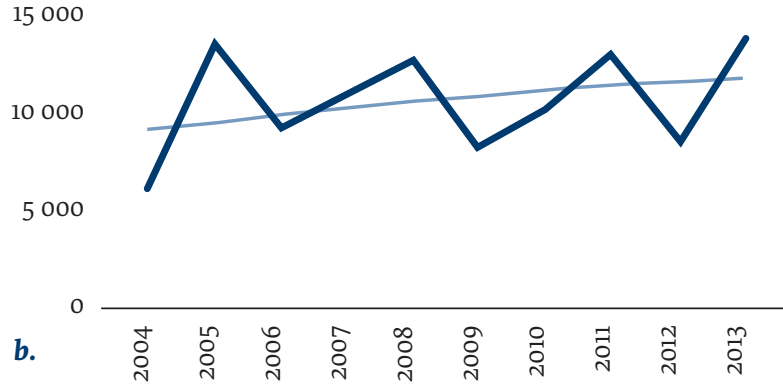

4000

3000

2000

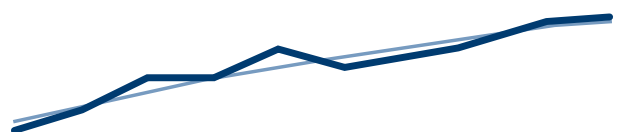

1000

d.
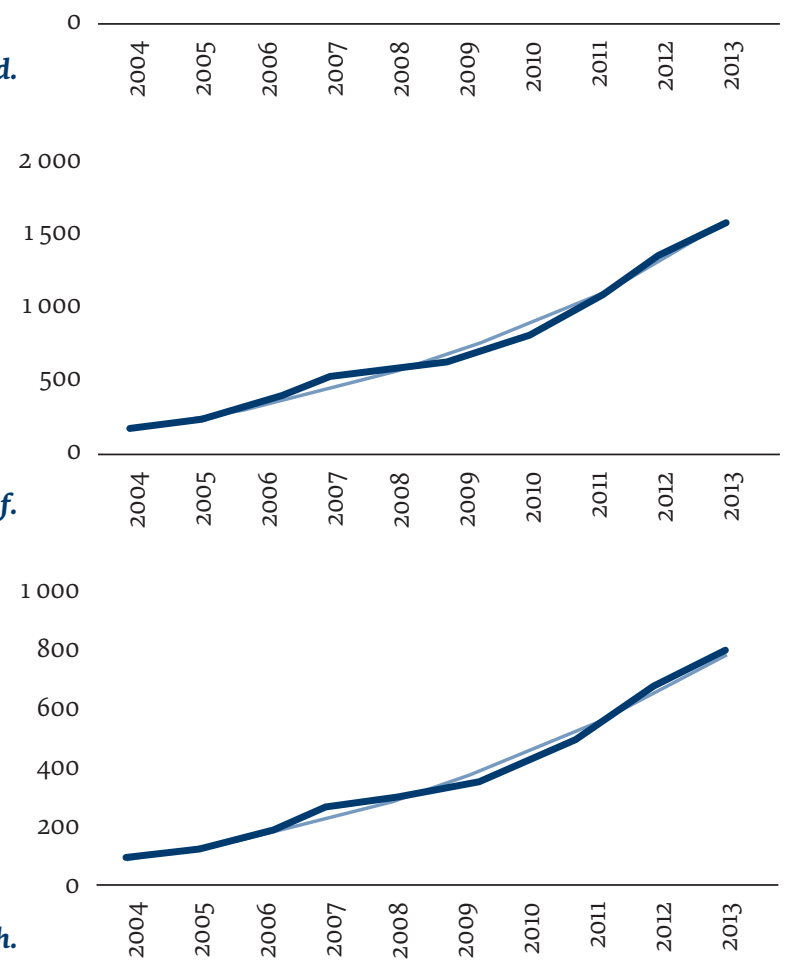

Thin lines represent corresponding second order polynomial trend lines for the two 5-year periods 2004-2008 and 2009-2013.

sible for the production of an average of nearly $64 \%$ of all biomedical research articles published from the Region during years 2004-2013 (Table 1). In 2004 this figure was $54 \%$, while in 2013 it had increased to $71 \%$.

In Egypt, a steady increase in biomedical and health research productivity is noted during 2004-2013 following a slow growth observed during 1988-2002 $(2,62)$. This increase in bulk research outputs has been accompanied by a three-fold increase in research density when data are normalized to population size; 0.69 per 100000 population per year during 1987-2004 vs. 2.49 publications per 100-000 population per year during 2004-2013 (Figure 3.a).
In the Islamic Republic of Iran, policies aimed at supporting scientific research resulted in a remarkable production of scientific publications and placed the country among the fastest growing countries in terms of scientific research, especially among the 20 countries with the most publications $(9,63)$. In the present study, the Islamic Republic of Iran is demonstrating an exponential increase in terms of publication outputs in biomedical and health sciences for the period from 2004 to 2013 (Figure 1.b). This trend seems to be a continuation of a pattern that started in year 2000 (unpublished data) and matches with similar independent analyses $(61,64,65)$. In recent years more attention was given to priority setting for research and enhancing use of research evidence 


\begin{tabular}{|c|c|c|c|c|}
\hline & Country & Institution & $\begin{array}{l}\text { Published } \\
\text { Articles }\end{array}$ & $\%$ \\
\hline 1. & I.R. Iran & Tehran University of Medical Sciences & 8457 & 6.0 \\
\hline 2. & I.R. Iran & Shahid Beheshti University of Medical Sciences & 4470 & 3.2 \\
\hline 3. & Saudi Arabia & King Saud University & 4444 & 3.2 \\
\hline 4. & Tunisia & Tunis El Manar University & 3579 & 2.5 \\
\hline 5. & Egypt & Cairo University & 3331 & 2.4 \\
\hline 6. & I.R. Iran & Shiraz University of Medical Sciences & 2986 & 2.1 \\
\hline 7. & I.R. Iran & Isfahan University of Medical Sciences & 2940 & 2.1 \\
\hline 8. & I.R. Iran & Islamic Azad University & 2291 & 1.6 \\
\hline 9. & Egypt & Mansoura University & 2256 & 1.6 \\
\hline 10. & Lebanon & American University of Beirut & 2254 & 1.6 \\
\hline 11. & Pakistan & Aga Khan University & 2214 & 1.6 \\
\hline 12. & I.R. Iran & Tabriz University of Medical Sciences & 2095 & 1.5 \\
\hline 13. & Tunisia & Sfax University & 2033 & 1.4 \\
\hline 14. & I.R. Iran & Mashhad University of Medical Sciences & 1971 & 1.4 \\
\hline 15. & Egypt & Ain Shams University & 1806 & 1.3 \\
\hline 16. & I.R. Iran & Tehran University & 1763 & 1.2 \\
\hline 17. & Kuwait & Kuwait University & 1744 & 1.2 \\
\hline 18. & I.R. Iran & Tarbiat Modares University & 1689 & 1.2 \\
\hline 19. & Egypt & Alexandria University & 1543 & 1.1 \\
\hline 20. & Saudi Arabia & King Faisal Specialist Hospital and Research Center & 1533 & 1.1 \\
\hline 21. & Tunisia & Monastir University & 1340 & 1.0 \\
\hline 22. & Jordan & Jordan University of Science and Technology & 1314 & 0.9 \\
\hline 23. & Egypt & National Research Center & 1306 & 0.9 \\
\hline 24. & UAE & United Arab Emirates University & 1254 & 0.9 \\
\hline \multirow[t]{2}{*}{25.} & Oman & Sultan Qaboos University & 1118 & 0.8 \\
\hline & Total & & 61701 & 43.8 \\
\hline
\end{tabular}

University data include data for affiliated teaching hospitals or research centres.

in national policy-making $(66,67)$. When publication numbers are normalized to the population size (number of publications per 100000 population), a similar trend is observed (Figure 3.f).

\section{The fragility of biomedical and health research in the EMR}

While the increase of biomedical and health research productivity in Egypt, Islamic Republic of Iran, and Saudi Arabia could be attributed to the considerable support for scientific and health research in these countries (68), the stagnant development of biomedical and health research in other parts of the EMR is attributed to the weak support to national health research systems in the Region (7), as well as to major socio-political instabilities that downplayed scientific endeavours in some of the most research-active countries.

In Tunisia, the formation of the Ministry of Scientific Research, Technology and Competency Development (MSRTCD) in 1994 represented an essential turning point for the promotion of the research sector in the country.
Policies aimed at supporting the research culture in Tunisia contributed to the creation of 139 research laboratories and 624 research units encompassing 23000 part-time and full-time researchers (69). Unfortunately, the political instability that emerged in the aftermath of the Tunisian Revolution in 2010 halted many of the research activities, and this is showing clearly in the plummeting rates of biomedical and health research outputs recorded in Tunisia from 2011 (Figure 1.e). Despite this, Tunisia publishes an average of 10.91 healthresearch articles/100 000 population per year and is only second to Kuwait in terms of performance per population size in the EMR (Figure 2).

In Kuwait, the rates of biomedical publications started to witness an undulating period from 2008 with succeeding rises and falls (Figure 3.b). A similar observation is recorded for the UAE, which suffered from a similar phenomenon after 2010, but with a quick recovery soon after in 2013 (Table 1).

Egypt witnessed socio-political instabilities similar to those that took place in Tunisia, yet the impact of such 


\begin{tabular}{|c|c|c|c|c|c|c|c|c|c|c|c|c|c|c|c|c|c|}
\hline บWA & & & 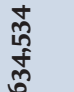 & $\hat{\sigma}$ & 2 & & in & 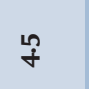 & & $\overleftarrow{z}$ & $\overleftarrow{z}$ & & กิ่ & $\stackrel{m}{0}$ & $\overleftrightarrow{z}$ & $\overleftarrow{z}$ & $\overleftarrow{z}$ \\
\hline $\begin{array}{r}\text { sәдедіü } \\
\text { qexy poitun }\end{array}$ & & & 索 & $\gtrless$ & $\stackrel{\infty}{\curvearrowright}$ & & $\underset{\substack{\text { N} \\
\text { d }}}{ }$ & N & & $\overleftarrow{z}$ & @ & & à & $\stackrel{\circ}{0}$ & ఫे & $\overleftarrow{\zeta}$ & $\sqrt{z}$ \\
\hline е!qexV Ipnes & & & $\begin{array}{l}\text { qu } \\
\text { ồ }\end{array}$ & i & $\stackrel{\infty}{\curvearrowright}$ & & $\underset{\sim}{\overrightarrow{0}}$ & กี & & $\underset{+}{+}$ & 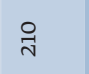 & & กั & $\stackrel{0}{0}$ & $\overleftrightarrow{z}$ & 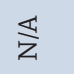 & $\overleftarrow{z}$ \\
\hline גeleo & हूँ & & $\begin{array}{l}\text { d } \\
\text { i }\end{array}$ & ๙ & $\infty$ & & $\begin{array}{l}\infty \\
\infty \\
\substack{c \\
j}\end{array}$ & สิ & & $\overleftrightarrow{s}$ & $\stackrel{\Im}{9}$ & & $\stackrel{+}{m}$ & $\stackrel{\stackrel{\leftrightarrow}{0}}{\circ}$ & f̛ & مे & $\stackrel{2}{\circ}$ \\
\hline иешо & 㩆 & & $\stackrel{t}{m}$ & i & 2 & & ஃ & $\underset{i}{\sim}$ & & $\stackrel{\leftrightarrow}{\leftrightarrow}$ & 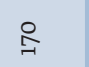 & & $\vec{\oplus}$ & $\stackrel{\overbrace{}}{0}$ & 今े & $\hat{\mathfrak{j}}$ & 苛 \\
\hline ग!емп) & & & బ్ & $\stackrel{\infty}{\curvearrowright}$ & 2 & & $\underset{\substack{n \\
N}}{n}$ & $\stackrel{i}{i}$ & & $\frac{\mathbb{s}}{z}$ & ส্ণ & & f̧ & न․ํ & $\stackrel{m}{0}$ & 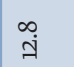 & $\stackrel{9}{0}$ \\
\hline u!̣xчеg & & & 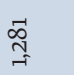 & 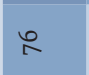 & $\stackrel{\infty}{\curvearrowright}$ & & ঃ & gे & & के & $\stackrel{\circ}{\text { กิ }}$ & & $\exists$ & 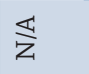 & ¿̊ & in & 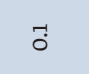 \\
\hline e!̣s!un $\mathrm{L}$ & & & 惫 & t & $\stackrel{\infty}{\wedge}$ & & ริ & 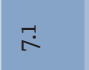 & & $\stackrel{\widetilde{i}}{\sim}$ & 유 & & $\stackrel{0}{1}$ & $\stackrel{\infty}{0}$ & $\ddot{\circ}$ & ळ్ & $\frac{\pi}{z}$ \\
\hline exq!T & & & $\begin{array}{l}n \\
\text { on } \\
0\end{array}$ & 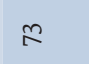 & E & & ఫ્ & $\dddot{q}$ & & Ș & o & & ઼ָ & $\overleftrightarrow{z}$ & $\overleftrightarrow{Z}$ & $\overleftrightarrow{\mathbb{z}}$ & $\frac{\pi}{z}$ \\
\hline иолеqәт & 苞 & & 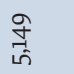 & $\stackrel{\infty}{\Upsilon}$ & $\infty$ & & کू & $\stackrel{\Upsilon 2}{\sim}$ & & $\stackrel{\leftrightarrow}{\dot{m}}$ & 品 & & $\underset{\substack{0 \\
0 \\
0}}{0}$ & $\stackrel{?}{\circ}$ & $\overleftrightarrow{z}$ & $\overleftrightarrow{\Xi}$ & $\sqrt{z}$ \\
\hline uеp.ol & 节 & & ב্ב & $\sqrt[5]{2}$ & 2 & & $\vec{\triangleright}$ & 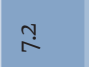 & & $\stackrel{+}{\leftrightarrow}$ & $\stackrel{\circ}{\infty}$ & & $\stackrel{4}{0}$ & ग्र & $\overleftrightarrow{\mathrm{z}}$ & $\frac{\pi}{z}$ & $\widehat{s}$ \\
\hline bexI & مे & & $\begin{array}{l}\stackrel{8}{2} \\
\text { f }\end{array}$ & $\hat{\sigma}$ & $g$ & & مٌ & กี่ & & $\stackrel{\text { ڤn }}{\circ}$ & $\stackrel{\nexists}{\pi}$ & & $\stackrel{0}{0}$ & $\begin{array}{l}\text { @ọ } \\
\text {. }\end{array}$ & $\overleftrightarrow{z}$ & $\stackrel{\llcorner}{j}$ & $\stackrel{\overrightarrow{0}}{\circ}$ \\
\hline uexI & & & 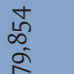 & a & $\gtrless$ & & $\underset{g}{g}$ & $\hat{\jmath}$ & & $\frac{\overleftrightarrow{z}}{z}$ & 욤 & & $\underset{\substack{0 \\
0}}{2}$ & $\stackrel{\infty}{0}$ & $\overleftrightarrow{z}$ & $\overleftrightarrow{\overleftarrow{z}}$ & $\overleftarrow{z}$ \\
\hline บวนว $\boldsymbol{X}$ & & & 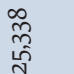 & $\Re$ & 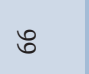 & & : & เं & & $\stackrel{\hat{i}}{i}$ & 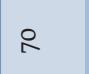 & & न & $\overleftrightarrow{z}$ & $\overleftrightarrow{z}$ & $\overleftrightarrow{\breve{z}}$ & $\overleftarrow{z}$ \\
\hline e!IKS & & & $\begin{array}{l}\hat{m} \\
\text { ò } \\
\text { d. }\end{array}$ & m & $\stackrel{\infty}{\infty}$ & & ఠ̊ & $m$ & & $\overleftrightarrow{s}$ & $\stackrel{\circ}{\circ}$ & & $\approx$ & $\stackrel{0}{0}$ & $\overleftrightarrow{\mathrm{z}}$ & $\overleftrightarrow{\mathrm{z}}$ & $\overleftrightarrow{\mathrm{z}}$ \\
\hline uepns & & & 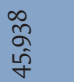 & 5 & $\mathscr{b}$ & & ה & ณ & & $\stackrel{\leftrightarrow}{\rightarrow}$ & 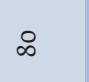 & & $\stackrel{\infty}{\infty}$ & : & $\frac{\mathbb{4}}{z}$ & $\frac{\mathbb{s}}{z}$ & $\frac{\mathbb{s}}{z}$ \\
\hline әu!̣sәГе & . & & $\frac{q}{q}$ & 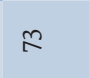 & 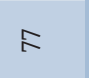 & & $\widehat{\widehat{y}}$ & $\circ$ & & $\frac{\mathbb{4}}{z}$ & $\frac{\mathbb{4}}{z}$ & & $\stackrel{\infty}{\infty}$ & ò & $\frac{\mathbb{4}}{z}$ & ìं & $\underset{\sim}{\stackrel{n}{\sim}}$ \\
\hline uefs!!yed & 冚 & & 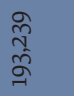 & $\mathscr{6}$ & $\hat{\sigma}$ & & $\stackrel{\nearrow}{\beth}$ & $\underset{i}{\infty}$ & & $\stackrel{\Re}{\circ}$ & 8 & & $\stackrel{0}{0}$ & $\stackrel{0}{0}$ & ปิ & $\widehat{\grave{g}}$ & $\stackrel{\text { Tิ }}{0}$ \\
\hline о5э010प & g. & & $\begin{array}{l}\text { gे } \\
\text { iे } \\
\text { în }\end{array}$ & ๑ి & n & & $\stackrel{\infty}{\check{\gamma}}$ & $\stackrel{0}{0}$ & & $\overleftrightarrow{\overleftarrow{z}}$ & \& & & 号 & O̊. & $\overleftrightarrow{z}$ & 正 & 艿 \\
\hline $1 \mathrm{~d} / \mathrm{8}_{\mathrm{g}}$ & & & 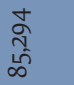 & 8 & I & & हे & है & & ָ̊. & 요 & & & : & $\stackrel{\infty}{\circ}$ & $\stackrel{\substack{+\dot{H}}}{2}$ & $\stackrel{\substack{c \\
i}}{i}$ \\
\hline !̣noq!! & & & నू & ৪ & $\Re$ & & ริ & $\infty$ & & $\frac{\overleftarrow{L}}{z}$ & 어 & & $m$ & $\stackrel{m}{0}$ & $\frac{\mathbb{Z}}{z}$ & $\overleftrightarrow{\frac{\pi}{z}}$ & $\overleftrightarrow{z}$ \\
\hline धпाएuos & : & & 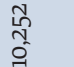 & n & 눈 & & $\overleftrightarrow{\mathbb{z}}$ & $\frac{\mathbb{z}}{z}$ & & $\overleftrightarrow{z}$ & $\frac{\pi}{z}$ & & สุ & $\overleftrightarrow{\mathrm{z}}$ & $\overleftrightarrow{\mathrm{z}}$ & $\overleftrightarrow{\mathrm{z}}$ & $\overleftrightarrow{\mathrm{z}}$ \\
\hline 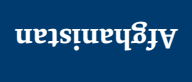 & 荺 & & $\begin{array}{l}\infty \\
\stackrel{0}{m}\end{array}$ & $\overrightarrow{0}$ & ๙ & & $\vec{\Xi}$ & $\vec{\infty}$ & & $\widehat{\hat{o}}$ & 요 & & $\stackrel{2}{0}$ & 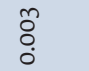 & $\frac{4}{2}$ & $\overleftrightarrow{\zeta}$ & $\overleftrightarrow{s}$ \\
\hline 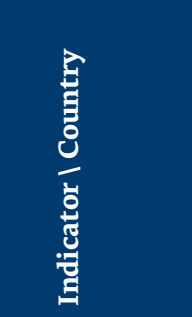 & 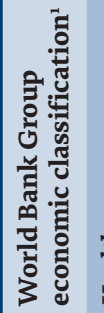 & 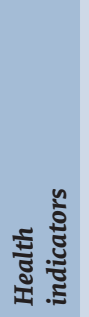 & 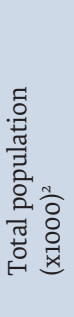 & 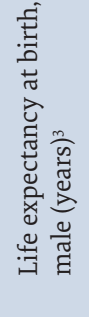 & 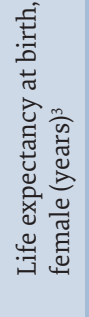 & 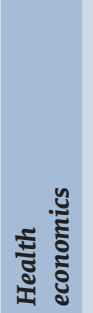 & 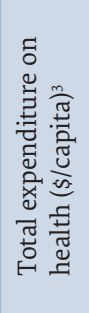 & 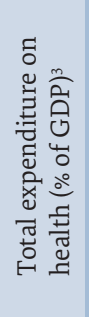 & 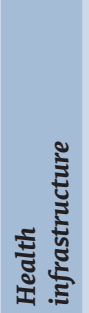 & 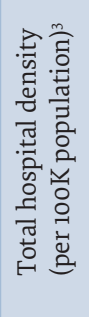 & 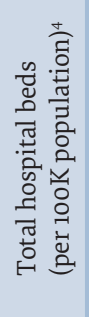 & 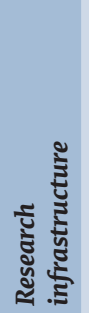 & 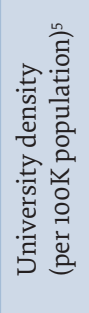 & 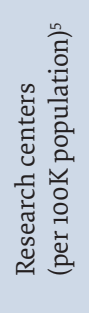 & 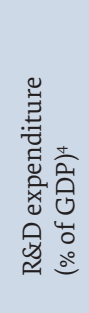 & 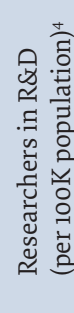 & 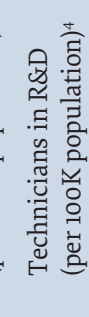 \\
\hline
\end{tabular}




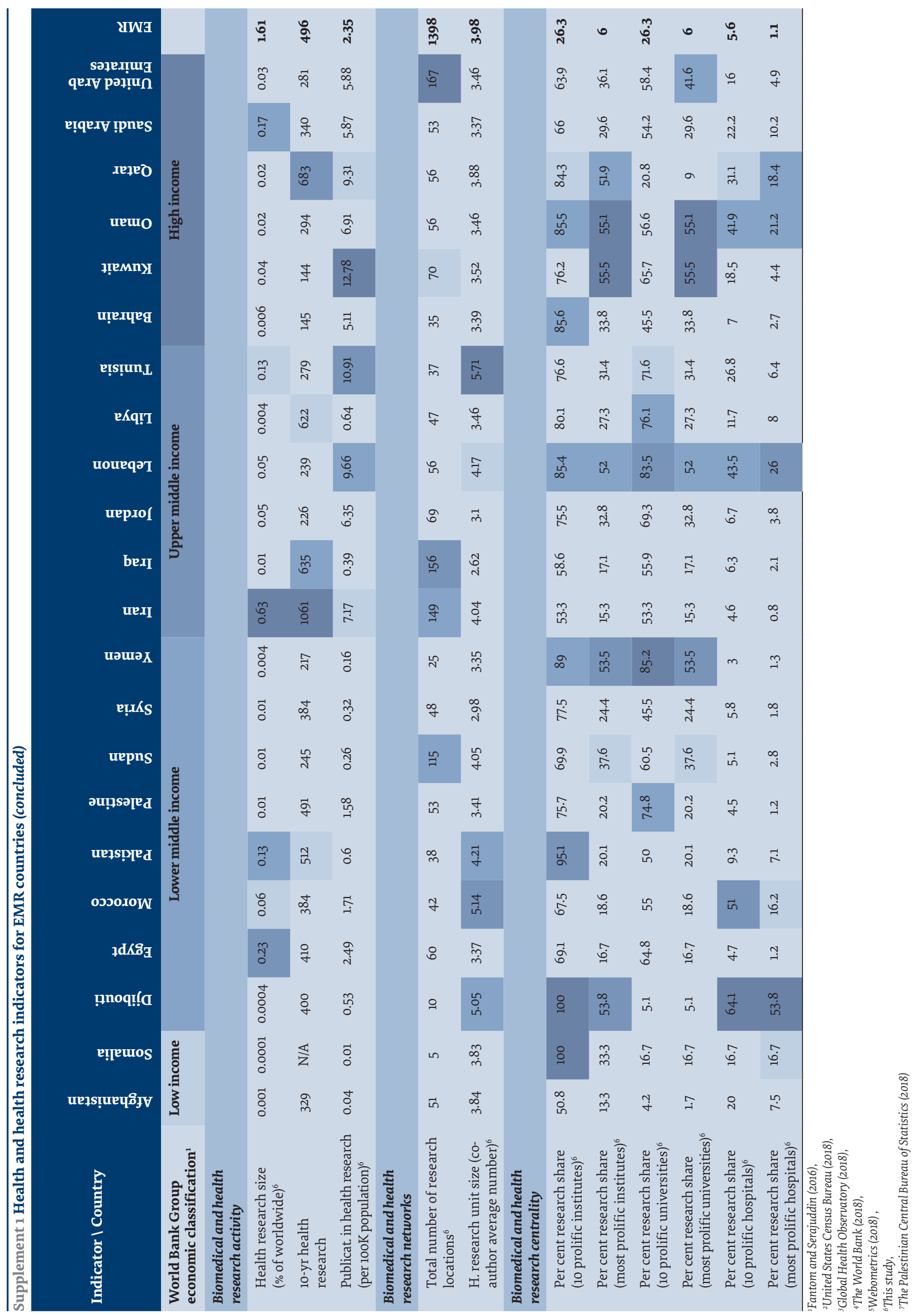


conditions on biomedical and health research output in the country was not substantial (Figure 1.c). Future investigations are needed to explore the factors that "protect" research activities in certain countries and try to transfer this knowledge to "immunize" the fragility of research activities in vulnerable countries. Some of the most valued suggestions in this regard would be to establish national research policies and to support and coordinate research activities among countries of the Region. If left unimmunized, microsystems in health research will be subject to turbulence in the administration and funding of research teams and even suppression of necessary prerequisites to foster agility and innovation.

\section{The contribution of academia}

The complexity of public health problems is becoming more challenging. Understanding and designing solutions for these problems require rigorous translation of fundamental scientific findings into clinical and public health outcomes. The scarcity of dedicated national research centres in many EMR countries has led biomedical and health research activities to become more concentrated in academic institutions (Table 3). Under optimal conditions, knowledge generated by biomedical and health research at academic institutions may be translated clinically and reach the market, thus providing patients with more treatment options (70). Such conditions could be made available through advocating cross-disciplinary research strategies and implementing holistic approaches to tackle complex questions that address public health in the EMR (71).

In the Islamic Republic of Iran, Tehran University of Medical Sciences contributed to $15.3 \%$ of the published research in the country (Table 2). The university is characterized by its large scientific community (estimated at 2004 research staff in the year 2009) and the production of comparatively high impact factor research publications $(19,72)$.

In Egypt, nearly $17 \%$ of the published research from Egypt was conducted at Cairo University and its affiliated educational hospitals (Table 2). Cairo University, Mansoura University, Ain Shams University, and Alexandria University produced altogether $45 \%$ of the total biomedical research outputs in the country. The 10 most research-active universities in Egypt had a combined output of $65 \%$ (unpublished data).

In Saudi Arabia, nearly 30\% of the published research was conducted at King Saud University (Table 2). This observation matches highly a report on biomedical research outputs covering the period 1982-2000 in which King Saud University had a contribution of $29.5 \%$ (37). Altogether, the 10 most research-active universities in Saudi Arabia had a combined output of $54.2 \%$ from the total biomedical and health research outputs in the country (unpublished data). All these observations are concomitant with a study that demonstrated universities contribute to an important share of scientific research activities globally (73). This trend could be driven mainly by stringent academic promotion requirements and the foundation of research parks, units, centres, and institutions in EMR countries with a wide range of activities including education, patient care, service and outreach, and technology transfer. Moreover, migrant scientists returning to the Region may also have a share in this trend since many are characterized by higher publication rates and relative access to international collaborative research networks $(74,75)$.

\section{Djibouti and Somalia}

Biomedical and health research activities in Djibouti and Somalia are relatively scant, as captured by PubMed. Djibouti has produced a total of only 38 articles in 10 years. Djibouti is a small country with a population of 792000 inhabitants, which translates into 0.5 articles published annually per 100000 population (Figure 3.d). Somalia presents the most extreme case among all studied countries with only seven articles published from 2004 to 2013 . The country has a population size almost equivalent to that of Tunisia - 10252000 inhabitants recorded at the end of 2013 (59). Such data translates into a meager value of 0.01 articles published annually per 100000 population (Figure 3.e). Such a situation should be enough to raise attention for investment in biomedical and health research and improvement of health status in both countries. One way to properly orient research activities in Djibouti and Somalia would be to focus on the top causes of death in these as reported by the Global Burden of Disease (GBD) observatory (76). The GBD data indicate that Djibouti and Somalia suffer mostly from communicable diseases, and what sets the two countries apart is the evolving factor of death in Somalia due to conflicts and terrorist activity (76). Hence, any support for research in the fields of communicable diseases and emergency preparedness and response would make a difference in the two countries.

The data collected in this study could not be extended to include research outputs beyond 2013, since PubMed does not offer an automated protocol to restrict searches for EMR citations based on the affiliations of primary authors. Health research production during subsequent years may have had different trends, especially when related to socio-political upheavals in the EMR.

The exclusive characteristics of the barrier-free PubMed search engine and the malleability of its builtin modules facilitate the implementation of massive search syntaxes and the seamless import of big data into offline systems where it can be analysed and leveraged. While hundreds of bibliometric studies relied on data exclusively extracted from PubMed, this strategy may have possible limitations since not all publications in scientific peer-reviewed EMR journals are cited in PubMed. However, this gap could be certainly bridged by complementing the investigation with data obtained from other search engines (e.g., The Index Medicus for the Eastern Mediterranean Region [IMEMR]).

The concerted efforts made to establish national programmes to combat communicable and noncommunicable diseases in the EMR, and the diffusion 
of translational biomedical research outcomes into health care delivery, are helping in the improvement of various health indicators in the Region. For example, the reduction in infant mortality ratios below the global average of 44.1 per 1000 live births and the increase in life expectancies beyond the global level of 66.1 years (77). However, dark shadows cloud this bright picture since the Region is going through a crucial geopolitical, socioeconomic, and, subsequently, critical health-care phase. Current wars, political unrest, ageing demographics and population growth in the EMR have major impacts on the Region's health and resources (78-80).

Investment in health research is disproportionately low in the EMR relative to estimates of disease burden in the Region (7). In fact, it is estimated to have only $1.1 \%$ of global research resources in 2013 (81). A study on health research outputs in Palestine indicates the presence of a mismatch between the health burden of certain disease conditions and the number of published research reports on those diseases (82). Such discordance between research output and disease burden was also demonstrated in a study that covered research on noncommunicable diseases in seven Arab countries (68). These pioneering observations are enough reason to further explore the qualitative, organizational, and social characteristics of biomedical and health research in the EMR and how it is aligned with the major health priorities in the Region.

\section{Conclusion}

Our study showed that 2.35 articles are published per 100 ooo population per year in the EMR, with only five countries contributing to $80 \%$ of all published articles during the study period (2004-2013). In many EMR countries biomedical and health research is incubated in academic institutions while in others research it is fostered within hospital settings. Collectively, the 25 most prolific EMR institutions were observed to publish $44 \%$ of all published biomedical and health research in the Region. Thus, the EMR has a long way to go; biomedical and health research needs greater encouragement and support in many countries and/or institutions, especially those found to be least prolific in our analysis, which is the job of different stakeholders, whether public and/or private, as well as funding agencies functional in the EMR. It is anticipated that the concentration of biomedical and health research in the EMR in academic institutions would help in translating knowledge into public health outcomes, if more suitable conditions are provided.

\section{Acknowledgments}

Facilities of the Faculty of Public Health at Jinan University, Tripoli, Lebanon, were utilized for this study. The authors would like to thank Dr Azza Hussein (Libya), Dr Niveen Abu-Rmeileh (Palestine), Dr Hyam Bashour (Syrian Arab Republic), Dr Samira Abdel Rahman (Sudan), Dr Adhra AlMawali (Oman), Dr Hanan Badr (Kuwait), Dr Raeda Abu AlRub (Jordan), and Dr Chokri Arfa (Tunisia) for their invaluable contributions. The authors alone are responsible for the views expressed in this publication and they do not necessarily represent the views, decisions, or policies of their institutions.

Funding: WHO Regional Office for the Eastern Mediterranean, Cairo, Egypt.

Competing interests: None declared.

\section{Géographie de la recherche en biomédecine et en santé dans la Région de la Méditerranée orientale}

\section{Résumé}

Contexte : Mesurer la production scientifique permet d'évaluer objectivement les systèmes de recherche en santé établis et de classer les pays en fonction de leurs résultats scientifiques. À notre connaissance, les tentatives visant à cartographier de manière systématique la production de la recherche en santé dans la Région de la Méditerranée orientale sont limitées.

Objectifs : Notre objectif consistait à réaliser une analyse bibliométrique détaillée de la recherche en biomédecine et en santé dans la Région de la Méditerranée orientale sur la période 2004-2013, en prenant en compte le pays du premier auteur.

Méthodes : Nous avons employé une stratégie de recherche améliorée dans PubMed afin d'obtenir des données précises sur la productivité de la recherche dans la Région de la Méditerranée orientale, limitant les articles aux revues, aux recherches originales et aux études de cas. Les données ont été normalisées de manière à pouvoir être comparées à celles de la production de la recherche au niveau international, représentée par le nombre total d'articles indexés dans PubMed par année de 2004 à 2013, rapporté au nombre d'habitant de chaque pays. Des lignes de tendances polynomiales d'ordre 2 ont été calculées, avec une comparaison de périodes quinquennales : 2004-2008 avec 2009-2013.

Résultats : L'examen de l'ensemble des données brutes a permis d'observer une tendance croissante indéniable. La part de la Région dans la recherche en santé mondiale était comprise entre $0,85 \%$ et $2,36 \%$ du total des publications indexées dans PubMed au cours de la période étudiée. Cinq pays ont produit $80 \%$ de l'ensemble des articles publiés pendant la période étudiée, à savoir la République islamique d'Iran (39\%), l'Égypte (14\%), l'Arabie saoudite (11\%), la Tunisie et le 
Pakistan (8 \% chacun). Au total, 2,35 articles ont été publiés chaque année pour 100000 habitants. Tandis que le Koweït conservait le nombre de publications par habitant le plus élevé (suivi de la Tunisie, du Liban, du Qatar et de la République islamique d'Iran), le Qatar, la République islamique d'Iran et l'Arabie saoudite ont enregistré la plus forte croissance de ce taux. Trois établissements universitaires représentaient plus de $10 \%$ de l'ensemble des publications dirigées par un chercheur de la Région. Collectivement, les 25 établissements les plus prolifiques de la Région de la Méditerranée orientale ont publié $44 \%$ de l'ensemble des articles de recherche en biomédecine et en santé publiés dans la Région.

Conclusions : La part mondiale globale de la Région de la Méditerranée orientale dans les publications de recherche en santé est inférieure à sa part mondiale en termes de population ou de richesse. La recherche en biomédecine et en santé doit être davantage encouragée et un soutien doit être apporté à de nombreux pays et/ou établissements de la Région de la Méditerranée orientale, en particulier à ceux qui s'avèrent être les moins prolifiques dans notre analyse. L'augmentation du nombre de publications universitaires sur la santé a été notable dans quelques pays seulement. La concentration de la recherche en biomédecine et en santé dans les établissements universitaires de la Région de la Méditerranée orientale devrait aider à traduire les connaissances en résultats de santé publique, si des conditions plus favorables sont mises en place.

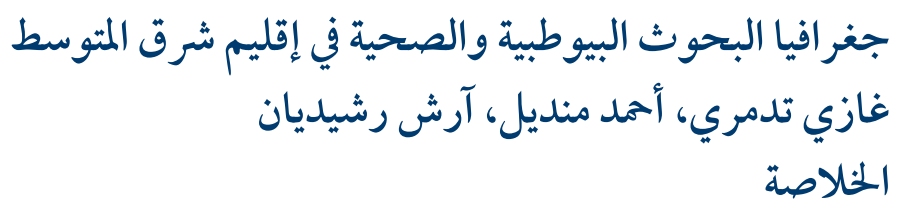

الخلفية: يتيح قياس المخرجات العلمية إجراء تقييم موضوعي لأنظمة البحوث الصحية وتصنيف البلدان وفقاً للإنجازات العلمية. حتى هذا

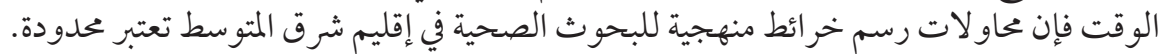

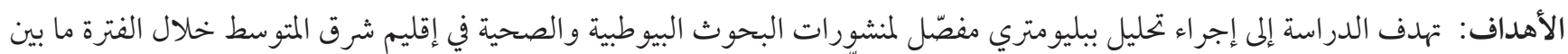

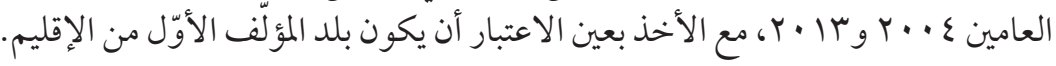

طرق البحث: قممنا بتطبيق إستراتيجية بحث محسّنة في قاعدة البيانات PubMed للحصول على بيانات دقيقة عن منشورات البحوث البيوطبية

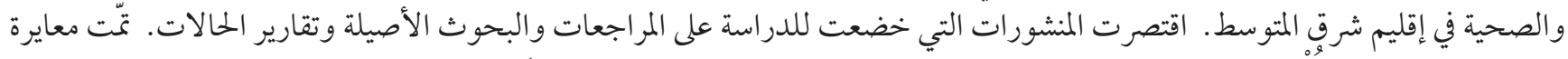

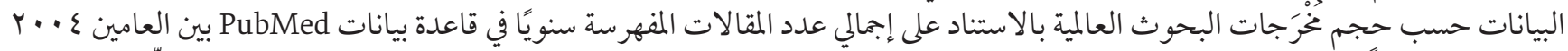

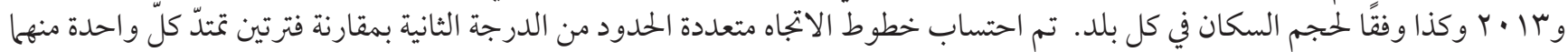

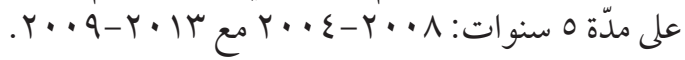

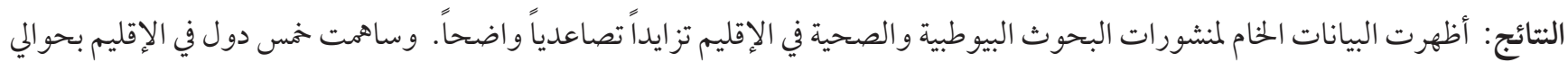

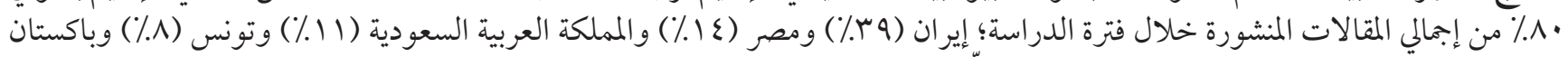

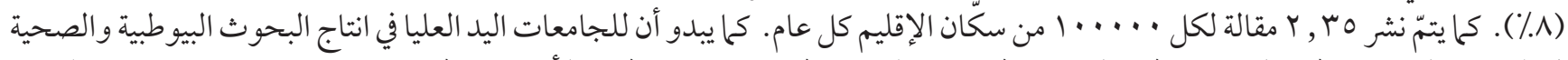

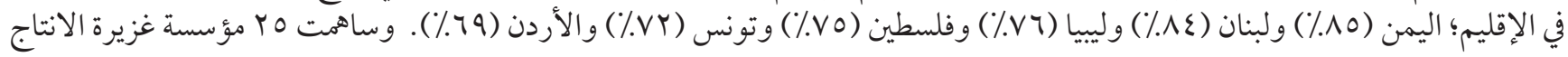

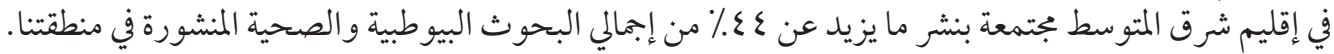

الاستنتاجات: يجب تشجيع البحوث الصحية ودعمها في العديد من بلدان و / أو مؤسّسات إقليم شرق المتوسط، لا سيّما تلك التي بيّنت الدراسة

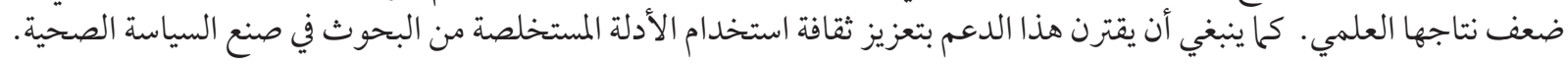

\section{References}

1. Bloomrosen M, Detmer DE. Informatics, evidence-based care, and research; implications for national policy: a report of an American Medical Informatics Association health policy conference. J Am Med Inform Assoc. 2010;17(2):115-23.

2. Tadmouri GO, Bissar-Tadmouri N. Biomedical publications in an unstable region: the Arab world, 1988-2002. Lancet. 2003;362:1766.

3. Global Health Observatory. Global Health Observatory (GHO) Data (http://www.who.int/gho/en/, accessed 22 February 2018).

4. Oxman AD, Lavis JN, Lewin S, Fretheim A. SUPPORT Tools for evidence-informed health Policymaking (STP) 1: What is evidence-informed policymaking? Health Res Policy Syst. 2009;7(Suppl 1):S1.

5. Gedik FG, Buchan J, Mirza Z, Rashidian A, Siddiqi S, Dussault G. The need for research evidence to meet health workforce challenges in the Eastern Mediterranean Region (Editorial). East Mediterr Health J 2018;24(9):811-812. https://doi. org/10.26719.2018.24.9.811.

6. Rashidian A, Mandil A, Mahjour J. Improving evidence informed policy-making for health in the Eastern Mediterranean Region. East Mediterr Health J 2017;23(12):793-794. https://doi.org/10.26719/2017.23.10.793. 
7. Kennedy A, Khoja TA, Abou-Zeid AH, Ghannem H, IJsselmuiden C; WHO-EMRO/COHRED/GCC NHRS Collaborative Group. National health research system mapping in 10 Eastern Mediterranean countries. East Mediterr Health J. 2008;14(3):502-17.

8. Mansoori P, Majdzadeh R, Abdi Z, Rudan I, Chan KY; Iranian CHNRI Health Research Priority Setting Group. Setting research priorities to achieve long-term health targets in Iran. J Glob Health 2018;8(2):020702. https://doi.org/10.7189/jogh.08.020702.

9. Massarrat S, Kolahdoozan S. Critical assessment of progress of medical sciences in Iran and Turkey: the way developing countries with limited resources should make effective contributions to the production of science. Arch Iran Med. 2011;14(6):370-7.

10. Jones AC, Geneau R. Assessing research activity on priority interventions for non-communicable disease prevention in low- and middle-income countries: a bibliometric analysis. Glob Health Action. 2012;5:1-13.

11. Ismail S, Nason E, Marjanovic S, Grant J. Bibliometrics as a tool for supporting prospective R\&D decision-making in the health sciences: strengths, weaknesses and options for future development. Rand Health Q. 2012;1(4):11.

12. Moed HF. Citation analysis in research evaluation. Dordrecht: Springer; 2005.

13. Wagner CS, Leydesdorff L. Mapping the network of global science: comparing international co-authorships from 1990 to 2000. Int J Technol Globalisation. 2005;1:185-208.

14. Pritchard A. Statistical biography or bibliometrics? J Doc. 1969;25(4):348-9.

15. White HD, McCain KW. Bibliometrics. Annu Rev Inform Sci. 1989;24:119-86.

16. Hood WW, Wilson CS. The literature of bibliometrics, scientometrics and informetrics. Scientometrics. 2001;52(2):291-314.

17. Smith R. Measuring the social impact of research. BMJ. 2001;323(7312):528.

18. Newman MEJ. Who is the best connected scientist? A study of scientific coauthorship networks. Lect Notes Phys. 2004;650:337-70.

19. Borzabadi S, Etemadi A. Scientometric analysis of the major Iranian medical universities. Arch Iran Med. 2011;14(3):222-3.

20. Rashidian A, Jahanmehr N, Jabbour S, Zaidi S, Soleymani F, Bigdeli M. Bibliographic review of research publications on access to and use of medicines in low-income and middle-income countries in the Eastern Mediterranean Region: identifying the research gaps. BMJ Open. 2013;3(10):e003332.

21. Helal R, Abou-ElWafa H, El-Gilany A. Publication productivity of faculty of medicine, Mansoura University indexed in PubMed. Ann Med Health Sci Res. 2014;4(Suppl 3):S278-85.

22. Mahmudi Z, Tahamtan I, Sedghi S, Roudbari M. Ranking Iranian biomedical research centers according to H-variants (G, M, A, R) in Scopus and Web of Science. Med J Islam Repub Iran. 2015;29:217.

23. Jamaluddine Z, Sibai AM, Othman S, Yazbek S. Mapping genetic research in non-communicable disease publications in selected Arab countries: first step towards a guided research agenda. Health Res Policy Syst. 2016;14(1):81.

24. Wheeler DL, Barrett T, Benson DA, Bryant SH, Canese K, Chetvernin V, et al. Database resources of the National Center for Biotechnology Information. Nucleic Acids Res. 2008;36(Database issue):D13-21.

25. PubMed. Homepage. Bethesda, MD: National Center for Biotechnology Information; 2018 (https://www.ncbi.nlm.nih.gov/ pubmed, accessed 8 February 2018).

26. Thompson DF. Geography of US biomedical publications, 1990 to 1997. N Engl J Med. 1999;340:817-8.

27. Hefler L, Tempfer C, Kainz C. Geography of biomedical publications in the European Union, 1990-98. Lancet. 1999;353:1856.

28. Uthman OA, Uthman MB. Geography of Africa biomedical publications: an analysis of 1996-2005 PubMed papers. Int J Health Geogr. 2007;6:46.

29. Lammers WJEP, Tahir A, Gondek V. Biomedical research publications from the United Arab Emirates during 1995. Emirates Med J. 1996;14:200-2.

30. Deleu D, Northway MG, Hanssens Y. Geographical distribution of biomedical publications from the Gulf Corporation Council countries. Saudi Med J. 2001;22:10-2.

31. Shaban SF, Abu-Zidan F. A quantitative analysis of medical publications from Arab countries. Saudi Med J. 2003;24:294-6.

32. Lammers WJEP, Gondek V. Medical publications from the United Arab Emirates: emerging impact of a new school? Emirates Med J. 1994;12:54-8.

33. Lammers WJEP, Tahir A. Medical publications in 1993 from the United Arab Emirates. Emirates Med J. 1995;13:80-1.

34. Lammers WJEP, Tahir A. Profile of medical research publications from the GCC countries, 1990-1994. Ann Saudi Med. 1996;16:666-9.

35. Lammers WJEP, Gaffar MS. National and international medical publications from the United Arab Emirates (1989-1998). Emirates Med J. 2000;18:235-8.

36. Neves K, Lammers WJ. Growth in biomedical publications and scientific institutions in the Emirates (1998-2004): an Arabian renaissance? Health Info Libr J. 2007;24:41-9.

37. Tadmouri GO, Tadmouri NB. Biomedical research in the Kingdom of Saudi Arabia (1982-2000). Saudi Med J.2002; 23:20-4.

38. Al-Bishri J. Evaluation of biomedical research in Saudi Arabia. Saudi Med J. 2013;34(9):954-9.

39. Latif R. Medical and biomedical research productivity from the Kingdom of Saudi Arabia (2008-2012). J Family Community Med. 2015;22(1):25-30. 
40. Ben Abdelaziz A, Harrabi I, Aouf S, Gaha R, Ghannem H. Typology of Tunisian medical research indexed in Medline from 1965 to 1999. Tunis Med. 2002;80:548-55.

41. Ben Abdelaziz A, Abdelali M, Khmakhem A. Bibliometric profile of Tunisian medical publications indexed in Medline from 2000 to 2003 party 1: productivity and cartography. Tunis Med. 2006;84:794-9.

42. Ben Abdelaziz A, Abdelali M, Khmakhem A, Ghannem H. Bibliometric profile of Tunisian medical publications indexed in Medline from 2000 to 2003 part 2: social relevance. Tunis Med. 2007a;85:9-14.

43. Ben Abdelaziz A, Abdelali M, Khmakhem A. Bibliometric profile of Tunisian medical publications indexed in Medline from 2000 to 2003 Part 3: International radiance. Tunis Med. 2007b;85:96-101.

44. Badrane H, Alaoui-el-Azher M. Moroccan Society for Biology Biomedical research in developing countries: the case of Morocco in the 1990s. Tunis Med. 2003;81:377-82.

45. Dakik HA, Kaidbey H, Sabra R. Research productivity of the medical faculty at the American University of Beirut. Postgrad Med J. 2006;82:462-4.

46. Tadmouri GO. Biomedical bibliometrics of a country with multiple identities: the case of Palestine. Annals of Alquds Medicine. 2006;1:63-8.

47. Ghaleh NR, Siadat F, Azizi F. Quantitative and qualitative assessment of biomedical publications from Iran, Pakistan and Egypt through their impact factor. J Pak Med Assoc. 2004;54:528-9.

48. Afifi M. Egyptian biomedical publications in PubMed, 1996-2005. J Egypt Public Health Assoc. 2007;82:91-104.

49. Bakoush O, Al-Tubuly AA, Ashammakhi N, Elkhammas EA. PubMed Medical Publications from Libya. Libyan J Med. 2007; AOP:070625.

50. Mazboudi M, Ben Abdelaziz A. Medical research productivity of Lebanon: a bibliometric study of papers indexed in Medline, 1985-2004. Tunis Med. 2010;88(8):579-85.

51. Rohra DK, Azam SI. Quantitative and qualitative analysis of PubMed-indexed biomedical publications in Oman from years 2005-2009. Oman Med J. 2011;26:160-5.

52. Zeeneldin AA, Taha FM. Qatar biomedical and cancer publications in PubMed between 2000 and 2012. Qatar Med J. 2014;2014:31-7.

53. Kolahdoozan S, Massarrat S. Progress of Iran in medical research. Acta Med Iran. 2016;54(11):690-5.

54. Mansouri A, Adhami Mojarad MR, Badfar G, Abasian L, Rahmati S, Kooti W, et al. Epidemiology of Toxoplasma gondii among blood donors in Iran: A systematic review and meta-analysis. Transfus Apher Sci. 2017;56(3):404-9.

55. Baradaran Eftekhari M, Sobhani Z, Eltemasi M, Ghalenoee E, Falahat K, Habibi E, et al. Research Ranking of Iranian Universities of Medical Sciences Based on International Indicators: An Experience From I.R. of Iran. Arch Iran Med. 2017;20(11):673-9.

56. Tadmouri GO, Mandil A, Rashidian A. Development of an Eastern Mediterranean Region search strategy for biomedical citations indexed in PubMed. East Mediterr Health J. 2017;23(9):619-29.

57. Tadmouri GO, Bissar-Tadmouri N. A major pitfall in the search strategy on PubMed. Saudi Med J. 2004;25:7-10.

58. National Library of Medicine. Changes coming to author affiliations. NLM Tech Bull. 2013;(394):b4.

59. United States Census Bureau. International Data Base. Washington, DC: United States Census Bureau; 2018 (https://www.census.gov/data-tools/demo/idb/informationGateway.php, accessed 8 February 2018).

6o. Rasolabadi M, Khaledi S, Khayati F, Kalhor MM, Penjvini S, Gharib A. Scientific Production of medical universities in the west of Iran: a scientometric analysis. Acta Inform Med. 2015;23(4):206-9.

61. Mohammadhassanzadeh H, Samadikuchaksaraei A, Shokraneh F, Valinejad A, Abolghasem-Gorji H, Yue C. A bibliometric overview of 30 years of medical sciences productivity in Iran. Arch Iran Med. 2010;13(4):313-7.

62. Zeeneldin AA, Taha FM, Moneer M. Past and future trends in cancer and biomedical research: a comparison between Egypt and the world using PubMed-indexed publications. BMC Res Notes. 2012;5:349.

63. Xu Q, Boggio A, Ballabeni A. Countries' biomedical publications and attraction scores. A PubMed-based assessment. Version 2. F100oRes. 2014 [revised 2015];3:292.

64. Radmard A, Khademi H, Azarmina P, Sadat-Safavi M, Nourai M, Kolahdoozan S. Iran biomedical sciences research output in 2003: a bibliographic analysis of Medline and Exerpta Medica databases. Arch Iran Med. 2005;8:180-3.

65. Ghasemi N, Rahimi S, Shahi S, Mokhtari H. Published Articles in PubMed-indexed journals from Tabriz University of Medical Sciences Faculty of Dentistry. J Dent Res Dent Clin Dent Prospects. 2012;6(4):160-2.

66. Badakhshan A, Arab M, Rashidian A, Gholipour M, Mohebbi E, Zendehdel K. Systematic review of priority setting studies in health research in the Islamic Republic of Iran. East Mediterr Health J 2018;24(8):753-769. https://doi.org/10.26719/2018.24.8.753.

67. Yousefi-Nooraie R, Rashidian A, Nedjat S, Majdzadeh R, Mortaz-Hedjri S, Etemadi A, et al. Promoting development and use of systematic reviews in a developing country. J Eval Clin Pract. 2009;15:1029-1034.

68. Sibai AM, Singh NV, Jabbour S, Saleh S, Abdulrahim S, Naja F, et al. Does published research on non-communicable disease (NCD) in Arab countries reflect NCD disease burden? PLoS One. 2017; 2(6):e0178401.

69. Madikizela M. The science and technology system of the Republic of Tunisia. Country studies: Arab States, Paris: UNESCO; 2005. 
70. Heus JJ, de Pauw ES, Leloux M, Morpurgo M, Hamblin MR, Heger M. Importance of intellectual property generated by biomedical research at universities and academic hospitals. J Clin Transl Res. 2017;3(2):5.

71. Maleki K, Hamadeh RR, Gholami J, Mandil A, Hamid S, Butt ZA, et al. The knowledge translation status in selected Eastern Mediterranean universities and research institutes. PLoS One. 2014;9(9):e103732.

72. Rezaei-Ghaleh N, Azizi F. The impact factor-based quality assessment of biomedical research institutes in Iran: effect of impact factor normalization by subject. Arch Iran Med. 2007;10(2):182-9.

73. Choung JY, Hwang G HR. National systems of innovation: Institutional linkages and performances in the case of Korea and Taiwan. Scientometrics. 2000;48:413-26.

74. Scellato G, Franzoni C, Stephan P. Migrant scientists and international networks. Res Policy. 2015;44(1):108-20.

75. Sweileh WM. Global research output in the health of international Arab migrants (1988-2017). BMC Public Health. $2018 ; 18(1): 755$.

76. Institute of Health Metrics and Evaluation (IHME). Country profiles (2016). (http://www.healthdata.org/results/country-profiles, accessed 1 March 2018).

77. EMRIMR. Eastern Mediterranean Region Indicator and Metadata Registry (http://gis.emro.who.int/EMRIMR/Domains.aspx, accessed 22 February 2018).

78. Maziak W. Global voices of science. Science in the Arab world: vision of glories beyond. Science. 2005;308(5727):1416-8.

79. Ben Taleb Z, Bahelah R, Fouad FM, Coutts A, Wilcox M, Maziak W. Syria: health in a country undergoing tragic transition. Int J Public Health. 2015;60 Suppl 1:S63-72.

80. Mokdad AH, Forouzanfar MH, Daoud F, El Bcheraoui C, Moradi-Lakeh M, Khalil I, et al. Health in times of uncertainty in the Eastern Mediterranean Region, 1990-2013: a systematic analysis for the Global Burden of Disease Study 2013. Lancet Glob Health. 2016;4(10):e704-13.

81. Røttingen JA, Regmi S, Eide M, Young AJ, Viergever RF, Ardal C, et al. Mapping of available health research and development data: what's there, what's missing, and what role is there for a global observatory? Lancet. 2013;382(9900):1286-307.

82. Albarqouni L, Elessi K, Abu-Rmeileh NME. A comparison between health research output and burden of disease in Arab countries: evidence from Palestine. Health Res Policy Syst. 2018;16(1):25. 